\title{
Doenças do Milho Causadas por Fungos do Gênero Stenocarpella
}

\author{
Ricardo T. Casa ${ }^{1}$, Erlei M. Reis ${ }^{2} \&$ Laércio Zambolim $^{3}$ \\ ${ }^{1}$ Centro de Ciências Agroveterinárias, Universidade de Santa Catarina, Cx. Postal 281, CEP 88520-000, Lages, SC, \\ e-mail:a2rtc@cav.udesc.br; ${ }^{2}$ Faculdade de Agronomia e Medicina Veterinária, Universidade de Passo Fundo, \\ Cx. Postal 611, CEP 99001-970, Passo Fundo, RS; ${ }^{3}$ Departamento de Fitopatologia, \\ Universidade Federal de Viçosa, CEP 36570-000, Viçosa, MG
}

(Aceito para publicação em 27/11/2006)

Autor para correspondência: Ricardo Trezzi Casa

CASA, R.T., REIS, E.M. \& ZAMBOLIM, L. Doenças do milho causadas por fungos do Gênero Stenocarpella. Fitopatologia Brasileira 31:427-439. 2006.

\section{RESUMO}

Os fungos Stenocarpella macrospora e Stenocarpella maydis podem causar podridão de semente, morte de plântula, podridão da base do colmo e da espiga e mancha foliar em milho, sendo comumente detectados nos grãos ardidos quando as espigas são infectadas. Os danos no rendimento e na qualidade de grãos causados especificamente por Stenocarpella ainda não foram devidamente quantificados. Os patógenos são encontrados praticamente em todas as regiões produtoras de milho do Brasil. A doença ocorre com maior intensidade em lavouras de monocultura, principalmente em pequenas propriedades rurais, e em lavouras produtoras de semente, onde o cereal é freqüentemente cultivado na mesma área. Os restos culturais de milho e as sementes infectadas constituem-se na principal fonte de inóculo primário. O inóculo constituído de picniosporos, produzido nos resíduos culturais, é disseminado à curta distância pelo vento e respingos d'água. A disseminação à longa distância ocorre pelas sementes. A infecção das plantas pode ser sistêmica, com inóculo na forma de micélio oriundo das sementes, e/ou pela penetração direta com germinação dos conídios nos sítios de infecção, como bainha foliar, lâmina foliar, pedúnculo e palha da espiga. A temperatura ótima para crescimento do micélio e germinação dos conídios de ambas espécies ocorre na faixa de $23{ }^{\circ} \mathrm{C}$ a $28^{\circ} \mathrm{C}$. As principais estratégias de controle baseiam-se na eliminação e/ou redução da fonte de inóculo primário, como uso de semente sadia, tratamento de sementes com fungicida do grupo dos benzimidazóis e rotação de culturas. Pouca informação existe sobre a tolerância da doença em híbridos comerciais no Brasil. A adubação equilibrada do solo e evitar elevada densidade de plantas também podem reduzir a infecção.

Palavras-chave adicionais: mancha de macrospora, podridão de diplodia, podridão branca da espiga, Zea mays.

\begin{abstract}
Maize diseases caused by fungi of the genus Stenocarpella

Stemocarpella macrospora and S. maydis may cause seed rot, seedling blight, stem and ear rot and leaf spot in corn. Normally these fungi are the main grain rot causal agent when ears are infected. The damage caused exclusively by Stenocarpella has not yet been determined. The pathogens are found in practically all maize-growing regions of Brazil. The major disease intensity occurs under corn monoculture, mainly in small farms and fields for seed production where corn is continuously cultivated. Corn debris and infected seed are the primary source of inoculum. The inoculum, consisting of conidia produced in plant debris, is disseminated at short distance by wind and rain splash. Long distance dissemination occurs by seeds. Plant infection may occur systemically with inoculum coming from seeds, as mycelium, and/or through direct penetration of leaf sheats, foliar blade, peduncle and ear husks, from spore deposition, germination and penetration. The optimal temperature for mycelial growth and conidial germination is between 23 and $28{ }^{\circ} \mathrm{C}$ for both fungi. The main strategies to control these diseases are based on the elimination and/or reduction of primary inoculum, the use of healthy seed, seed treatment with fungicide of the benzimidazoles group and crop rotation. There is little information about disease resistance in commercial hybrids in Brazil. Balance of soil fertility and avoidance of high plant population may also help to reduce the infection.
\end{abstract}

Additional keywords: macrospora leaf spot, diplodia stem rot, white ear rot, Zea mays.

\section{INTRODUÇÃO}

O milho (Zea mays L.) é um dos cereais mais cultivados no mundo, com destaque pelo papel que cumpre na cadeia alimentar e por seu valor agronômico no sistema plantio direto. No Brasil, na safra agrícola de 2004/05, a área cultivada foi de 12,208 milhões de hectares, com produção de 35,007 milhões de toneladas de grãos (Conab, 2006). O rendimento médio nacional de $2.867 \mathrm{~kg} / \mathrm{ha}$ é considerado baixo, em virtude do potencial produtivo da cultura.

As doenças do milho, principalmente aquelas causadas por fungos, podem comprometer o potencial de rendimento da cultura (White, 1999). A expansão da área cultivada em 
plantio direto proporcionou uma alteração no microclima e na biologia do agroecossistema, com reflexos nas populações dos agentes causais das doenças do milho (Reis et al., 2004). A presença dos restos culturais sobre a superfície do solo, beneficia a sobrevivência de muitos fitopatógenos, fazendo com que doenças antigas ressurjam com maior intensidade e novas doenças se manifestem. A diplodia causada pelos fungos Stenocarpella macrospora e $S$. maydis é uma doença do milho antiga no Brasil, conhecida por causar podridão em espigas. Hoje as duas espécies de Stenocarpella podem ser detectadas em todas as regiões produtoras de milho causando sintomas de podridão do colmo de diplodia, podridão branca da espiga e mancha de macrospora em folhas. O objetivo dessa revisão é descrever o ciclo das relações patógenohospedeiro e as principais estratégias de controle no patossistema Stenocarpella-milho.

\section{NOMES COMUNS}

O nome comum dado a uma doença normalmente relaciona-se ao local de infecção no hospedeiro, ao tipo de sintoma e a presença e coloração dos sinais do patógeno, de modo a serem úteis à diagnose. Como os agentes causais, citados nessa revisão, colonizam e exibem os sintomas principalmente em colmos e espigas de plantas de milho, em geral, a doença é denominada de podridão do colmo ou da espiga. É importante ressaltar que outras espécies de fungos também colonizam colmos e espigas de milho causando podridões. No Brasil, quando os sintomas manifestam-se no colmo, a doença é conhecida como podridão do colmo causada por Diplodia (Balmer \& Pereira, 1987; Pereira, 1997), podridão de diplodia, podridão da base do colmo (Reis \& Casa, 1996) e podridão de Diplodia maydis (Fernandes \& Oliveira, 1997). Em espiga, a doença é denominada de podridão da espiga causada por Diplodia (Balmer \& Pereira, 1987, Pereira, 1997) e podridão de diplodia ou podridão branca da espiga (Reis \& Casa, 1996; Fernandes \& Oliveira, 1997). O sintoma de mancha foliar tem sido denominado de mancha de Diplodia macrospora (Fernandes \& Oliveira, 1997), mancha foliar de diplodia macrospora ou mancha de macrospora (Reis et al., 2004).

Nesse trabalho serão empregados os nomes comuns de podridão do colmo de diplodia, podridão branca da espiga e mancha de macrospora.

\section{ETIOLOGIA E TAXONOMIA}

Os fungos Stenocarpella maydis (Berkeley) Sutton [Sin. Diplodia maydis (Berkeley) Saccardo; D. zeae (Schweinitz) Leveille] e $S$. macrospora (Earle) Sutton [Sin. $D$. macrospora Earle] pertencem a Classe Ascomycetes e Ordem Dothideales. Estas duas espécies apresentam no campo, em seu ciclo biológico, somente a forma anamórfica (imperfeita ou assexuada), e podem causar podridão do colmo, da espiga e mancha foliar.

Sutton (1980), em revisão dos “Coelomycetes”, propôs que as duas espécies $D$. maydis e $D$. macrospora, encontradas em colmos, sementes e folhas do milho, fossem incluídas no gênero Stenocarpella Syd., baseado na conidiogenese como uma característica taxonômica. Por outro lado, em 1985, na revista "Plant Disease", foi publicado uma lista de Nomes Comuns de Doenças de Plantas (Committee on Standartization of Common Names For Plant Diseases, 1985), na qual o gênero Diplodia era preferido para identificar as espécies em discussão. Alguns pesquisadores na África do Sul (Chambers, 1988; Flett \& Wehner, 1991; Bensch, 1995) e nos Estados Unidos (Latterell \& Rossi, 1983; Klapproth \& Hawk, 1991; Morant et al., 1993), adotam Stenocarpella para identificar as espécies D. maydis e D. macrospora. O gênero Stenocarpella também foi aceito em publicações da Sociedade Americana de Fitopatologia (American Phytopathological Society - APS), como verificado na terceira edição do compêndio de doenças do milho (White, 1999). Considerando as informações da literatura consultada, verifica-se que a classificação taxonômica dos agentes causais descritos nesta revisão, apresenta como base científica as descrições de Sutton \& Waterston (1966a,b) e a revisão de Sutton (1980). Sutton (1980) justifica que características da conidiogenese levaram as espécies a serem incluídas num gênero distinto de Diplodia, pois Stenocarpella apresenta células conidiogênicas enteroblásticas e fialídicas e, Diplodia, células conidiogênicas holoblásticas. Adenominação Stenocarpella vem sendo utilizada há pouco tempo no Brasil e será adotada nessa revisão. O fungo Diplodia frumenti Ell. \& Ev. também pode incitar podridão do colmo e da espiga em milho, porém, essa espécie continua pertencendo ao gênero Diplodia. O fungo já foi relatado no Brasil (Ito et al., 1979), mas sua ocorrência em lavouras comerciais não vem sendo detectada.

Stenocarpella maydis apresenta picnídios subepidérmicos, globosos ou alongados, com coloração marrom-escura a preta, paredes grossas, diâmetro de 150$300 \mu \mathrm{m}$ e um ostíolo protuberante papilado. Os conidióforos são usualmente ausentes. Apresentam células conidiogênicas enteroblásticas, fialídicas, cilíndricas, formadas nas células internas da parede do picnídio. Os conídios são pardosoliva a pardos, cilíndricos, fusiformes, retos a ligeiramente curvados, medindo 15-34 x 5-8 $\mu \mathrm{m}$, bicelulados $\mathrm{e}$ comumente com 1 septo (0-2) (Sutton \& Waterston, 1966a; Sutton, 1980). Stenocarpella macrospora apresenta picnídio e conídios semelhantes aos descritos para S. maydis, porém seus esporos são 2-3 vezes maiores, medindo 44-82 x 7,5-11,5 $\mu \mathrm{m}$ e apresentando 1-2 septos (1-3) (Sutton \& Waterston, 1966b; Sutton, 1980) (Figura 1A).

As medidas de comprimento e largura dos conídios de $S$. macrospora e $S$. maydis obtidos de diferentes órgãos infectados e a partir de meio de cultura de batata-sacaroseágar (BSA) (Casa, 1997) coincidem com os limites descritos na literatura (Tabela 1). As duas espécies podem ser diferenciadas com base na forma, tamanho, número de células e cor dos conídios (Figura 1A), pela coloração das colônias em meio de cultura (Reis et al., 2004) ou em papel filtro no "Blotter Test" (Mário \& Reis, 2001). Em meio de 

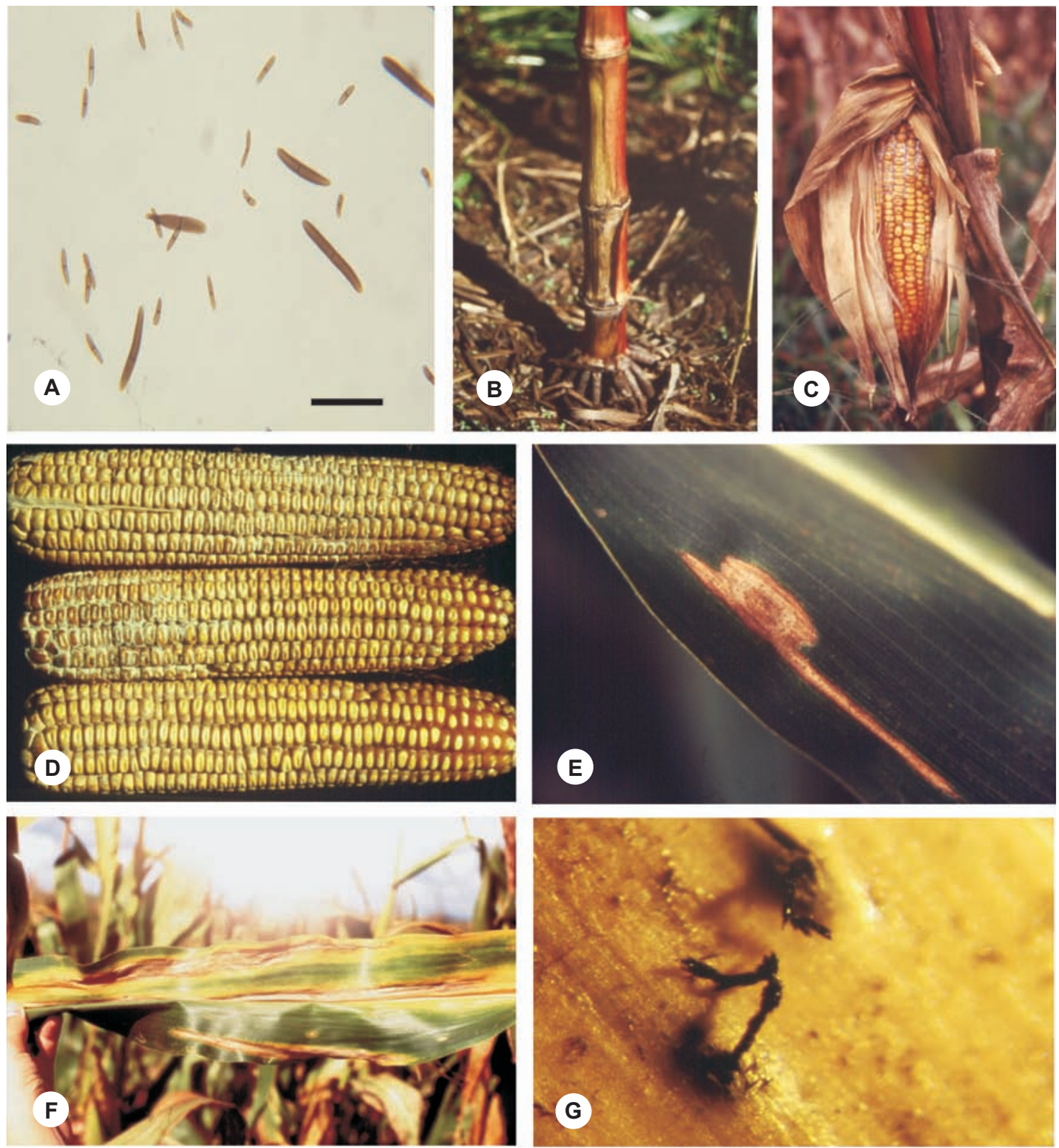

FIG. 1 - A. Conídios de Stenocarpella maydis (menores) e $S$. macrospora (maiores) Barra = $50 \mu$ m; B. Sintoma de podridão de diplodia em colmo; C. Sintoma de podridão branca da base da espiga; D. Espigas de milho severamente infectadas por Stenocarpella; E. Lesão inicial da mancha de diplodia macrospora; F. Sintomas de mancha foliar de diplodia macrospora; G. Cirros de conídios de Stenocarpella macrospora.

cultura de BSA, os fungos apresentam crescimento micelial rápido, com micélio aéreo e cotonoso, cobrindo a placa de Petri de $90 \mathrm{~mm}$ de diâmetro em 5-6 dias. Com 10 dias as colônias das duas espécies apresentam cor branca. Aos 15 dias, a colônia de $S$. maydis apresenta cor superficial salmão-escura, enquanto que $S$. macrospora permanece com a coloração superficial branca (Casa, 1997; Reis et al., 2004). Mário \& Reis (2001) verificaram que as colônias de $S$. macrospora permanecem brancas a bege 15 dias após a incubação das sementes em "Blotter Test", enquanto que $S$. maydis, originalmente branca, tornam-se pardo-escuras.
A formação de picnídios ocorre sobre os grãos em teste de patologia de sementes pelo método de "Blotter Test" ou em meios de cultura agarizados (BSA, farinha de milho e farinha de aveia) e em pedaços de folha de milho superficialmente embebidos nestes meios agarizados (Latterell \& Rossi, 1983; Casa et al., 1998a). Os fungos também podem produzir picnídio quando o micélio do fungo entra em contato com a parede de placas de Petri ou caixas de acrílico do tipo gerbóx. A adição de biotina ao meio de cultura pode estimular a esporulação de $S$. macrospora (Morant et al., 1993). 
TABELA 1 - Dimensão ( $\mu \mathrm{m})$ dos conídios de Stenocarpella maydis e $S$. macrospora obtidos em diferentes substratos comparados com mensurações descritas na literatura

\begin{tabular}{lcc}
\hline \hline Substratos & S. maydis & S.macrospora \\
\hline Batata-sacarose-ágar & $17-31 \times 4-7$ & $37,5-87 \times 6-12,5$ \\
Colmo & $18-32 \times 4-7$ & $44-93 \times 6-12$ \\
Folhas & - & $39-85 \times 6-12$ \\
Grãos de milho & $19-35 \times 4-7$ & $44-92 \times 6-12$ \\
Grãos de sorgo ${ }^{1}$ & $19-33 \times 4-7$ & - \\
Sabugo & $19-36 \times 4-7$ & - \\
Média & $\mathbf{1 8 , 4 - 3 3} \times \mathbf{4 - 7}$ & $\mathbf{4 1 , 1 - 8 9 , 2} \times \mathbf{6 - 1 2 , 1}$ \\
Eddins (1930) & $17-33 \times 3-7$ & $43-95 \times 6-13$ \\
Sutton \& Waterston (1966 a,b) & $15-34 \times 5-8$ & $44-82 \times 7,5-12,5$ \\
Ram et al. (1973) & - & $26,7-100,7 \times 5,7-11,5$ \\
Marasas \& Van Der Westhuizen (1979) & $15-37 \times 5-6$ & $55-106 \times 6-11$ \\
\hline
\end{tabular}

${ }^{1}$ utilizado para multiplicação de inóculo Fonte: Casa (1997)

\section{VARIABILIDADE DE Stenocarpella macrospora e de $S$. maydis}

$\mathrm{Na}$ literatura consultada não se encontrou relato da presença de raças de $S$. macrospora e $S$. maydis. Sabe-se, no entanto, da existência de variação no grau de agressividade entre diferentes isolados do patógeno. Hoppe (1936), estudando o antagonismo entre as espécies de Stenocarpella a partir de 21 isolados de $S$. maydis e de 4 isolados de $S$. macrospora, verificou que, em inoculações feitas em espigas com diferentes combinações entre três isolados de $S$. maydis e um de $S$. macrospora, havia uma ação antagônica entre eles, uma vez que em isolamentos realizados após o apodrecimento das espigas inoculadas, apenas um dos isolados foi recuperado. A reação antagônica inter e intraespecífica de $S$. maydis e $S$. macrospora pode ser visível pelo escurecimento do micélio e do meio de cultura quando as hifas de cada colônia juntam-se quando os fungos são cultivados em meio agarizado (Hoppe, 1936). Casa et al. (1998a) também detectaram o antagonismo inter e intraespecífico em colônias desenvolvidas em meio de BSA em análise de patologia de sementes com material incubado a $25^{\circ} \mathrm{C}$ e fotoperíodo de $12 \mathrm{~h}$, durante 10 a 12 dias.

Mais recentemente, Latterell \& Rossi (1983), comparando a patogenicidade dos fungos, verificaram que $S$. macrospora é mais agressivo do que $S$. maydis durante os estádios iniciais de desenvolvimento da planta. Rheeder et al. (1990) relataram uma associação negativa entre as espécies crescendo no mesmo lugar, sendo que $S$. macrospora restringiu o crescimento de $S$. maydis em plântula.

Dorrance et al. (1999), comparando 46 isolados de S. maydis oriundo de empresas de milho e de laboratórios fitopatologia dos Estados Unidos e da África do Sul, demonstraram baixo nível de polimorfismo de isoenzimas, com pequena variação para 10 enzimas avaliadas, sendo detectadas $\alpha$-esterase, hexose quinase e malato dehidrogenase. Os autores esperavam maior variação em função da agressividade do patógeno. A especialização do fungo ao hospedeiro é uma das justificativas para limitada variação em izoenzimas. Não foram encontrados na literatura informações sobre forma teleomórfica de $S$. macrospora e $S$. maydis.

\section{HISTÓRICO E OCORRÊNCIA}

O fungo $S$. maydis foi descrito pela primeira vez em 1884 (Saccardo, 1944) nos Estados Unidos, e desde então foi relatado nos cinco continentes (Sutton \& Waterston, 1966a). A espécie $S$. macrospora foi relatada pela primeira vez sobre colmos de milho no ano de 1896 em Auburn, Alabama, Estados Unidos (Earle, 1897).

A freqüência de detecção das espécies em colmos de milho no estado da Flórida, Estados Unidos, foi de 80,3\%, $16,5 \%$ e 3,2\%, respectivamente, para $S$. maydis, $S$. macrospora e D. frumenti (Eddins, 1930), sendo que alguns colmos apresentaram os picnídios de duas espécies e, em poucos casos, a presença das três espécies. Koehler \& Boewe (1957), examinando colmos de milho infectados durante os anos de 1946, 47 e 48 no estado de Illinois, Estados Unidos, verificaram porcentagem média de infecção de $31 \%$ para $S$. maydis e 25,8\% para Gibberella zeae (Schw.) Petch. Em 1959, também no estado de Illinois, Hooker \& White (1976) relataram que $S$. maydis foi encontrado em $86,3 \%$ das lavouras avaliadas, mas em 1975 somente 5,0\% de lavouras apresentavam o patógeno. $\mathrm{O}$ declínio de S. maydis foi atribuído à especificidade do fungo ao hospedeiro e ao desenvolvimento de cultivares superiores do ponto de vista de resistência genética pelos programas de melhoramento genético. No entanto, Anderson \& White (1987) relataram aumento da incidência de $S$. maydis causando podridão do colmo, com valores de $38,5 \%$ e $11,1 \%$ das lavouras amostradas, respectivamente, nos anos de 1982 e 1983.

$\mathrm{Na}$ África do Sul, o fungo S. macrospora foi relatado 
pela primeira vez por Marasas \& Van Der Westhuizen (1979) causando mancha foliar e podridão da espiga, que são, atualmente as principais doenças da cultura do milho naquele país (Flett \& Wehner, 1991; Bensch, 1995). Em 1980, $S$. macrospora foi relatado pela primeira vez na Nicarágua causando mancha foliar (Llano \& Schieber, 1980). A presença de $S$. maydis e $S$. macrospora também foi detectada em número significativo de amostras de sementes de milho obtidas de países da América Central, África e Ásia (Macdonald \& Chapman (1997).

No Brasil, a ocorrência de $S$. macrospora foi relatada pela primeira vez por Johann (1935) no estado de São Paulo causando podridão em sementes. Porém, os sintomas de mancha foliar somente foram relatados em 1973 na Bahia, realizandose também o teste de patogenicidade e a descrição morfológica do fungo (Ram et al., 1973). Apesar da existência de inúmeros trabalhos sobre S. maydis no Brasil, a prova de patogenicidade e a mensuração das estruturas reprodutivas foi realizada recentemente (Casa, 1997). A presença de $D$. frumenti causando podridão em espigas no Brasil foi relatada pela primeira vez em 1979 (Ito et al., 1979). No estado de Tocantins, Morello et al. (1994), em levantamento de 42 cultivares de ciclo normal, observaram que $15,9 \%$ das espigas de milho apresentaram sintomas de podridão, sendo que 19,1\% destas estavam colonizadas por Stenocarpella sp. Em testes de patologia de sementes de milho, S. maydis foi a espécie com maior freqüência de deteç̧ão (Oliveira \& Mello, 1986; Reis et al., 1995; Pinto, 1998). Hoje, o fungo S. macrospora é detectado com alta freqüência em sementes, fato atribuído ao aumento na ocorrência e intensidade da doença nas lavouras da Região Sul do Brasil (Casa et al., 2000) e pela disponibilidade de metodologia na identificação do fungo (Casa et al., 1998a,b; Mário \& Reis, 2001). A espécie $S$. macrospora também foi encontrada causando mancha foliar em lavouras de milho em todas as regiões do Brasil, porém não identificada devidamente, pois é confundida com a helmintosporiose comum. Denti \& Reis (2003), avaliando o efeito da monocultura e da rotação de culturas na incidência e nos danos causados pelas podridões do colmo, relataram que S. maydis e $S$. macrospora foram, na ordem de incidência, o segundo e o quarto fungo isolado das plantas sintomáticas.

\section{DANOS}

Na Região Sul do Brasil, os fungos $S$. maydis e $S$. macrospora estão relacionados com a germinação de sementes, emergência e estabebelecimento de plântulas, podridões do colmo e da espiga e mancha foliar (Casa et al., 2000; Reis \& Casa, 2001). O efeito negativo sobre a germinação de sementes indica que os fungos atacam e matam o embrião (Clayton, 1927; Casa, 1997). Nos casos onde a semente germina e a plântula emerge infectada, o vigor da planta sobrevivente é comprometido.

As podridões do colmo podem ser consideradas as doenças mais importantes na cultura do milho, ocorrem em todas as lavouras, todas as safras de cultivo, com incidência e severidade variada. Nos Estados Unidos, Shurtleff (1992) relatou danos de 10 a 20\%. No Brasil, Nazareno (1989) detectou incidência de 15 a $85 \%$ e reduções no rendimento de grãos de 12 a 40\%. Posteriormente, Denti \& Reis (2003) determinaram incidências de 4 a $72 \%$ com reduções no rendimento variando de 0,67 a $50 \%$. A podridão do colmo interfere no desenvolvimento normal da planta, afetando suas funções, ocasionando quebra da base do colmo, acamamento e morte prematura da planta (Shurtleff, 1992; Reis \& Casa, 1996). O dano causado pela morte prematura da planta, no final do ciclo da cultura, reflete no processo de enchimento de grãos. Quando ocorre acamamento, as espigas apresentam menor peso e algumas deixam de ser colhidas mecanicamente, o que acarreta um prejuízo maior ao produto devido à maior demanda de tempo requerido na colheita. Outro tipo de dano ocorre quando as espigas das plantas acamadas entram em contato como o solo, resultando no comprometimento da qualidade do grão. Durante três anos, Michaelson \& Christensen (1953) determinaram redução no rendimento grãos devido à podridão do colmo, chegando a danos de $9,7 \%$ causado por $S$. maydis. Wilcoxson (1962), avaliando as podridões do colmo em 16 híbridos comerciais, verificou dano de até $17 \%$, sendo mais severo quando a inoculação das plantas ocorreu 9-10 semanas antes da colheita. Redução de 5\% no rendimento de grãos foi obtido a partir de inoculações no colmo com S. maydis (Singh \& Sharma, 1974; Natti \& White, 1981).

A podridão branca da espiga pode causar redução na produtividade e na qualidade dos grãos colhidos. Muitos fungos causadores de podridão da espiga produzem micotoxinas que podem afetar também o valor econômico do grão e o valor nutricional da ração (Molin \& Valentini, 1999). Shurtleff (1992) e White (1999) não mencionam Stenocarpella como produtor de micotoxinas. No entanto, Cutler et al. (1980) relatam uma toxina denominada diplodiol produzida por $S$. macrospora, enquanto que Williams et al. (1992) descrevem a ocorrência de uma doença chamada diplodiose em patos jovens, ratos, bovinos e ovelhas e causada por uma toxina ainda não identificada que é produzida por S. maydis. A mancha de macrospora detectada com maior freqüência e intensidade nas lavouras de milho conduzidas em monocultura (Casa et al., 2000; Reis \& Casa, 2000). Além de infectar as folhas e, em muitas situações, dilacerar o tecido foliar necrosado, reduzindo a área foliar da planta, a doença torna-se mais grave em virtude da grande produção de inóculo sobre lesões, que contribui para o aumento do potencial de inóculo para a infecção do colmo e da espiga.

No Brasil, os danos e as perdas causadas exclusivamente por $S$. maydis e S. macrospora ainda não foram quantificados. Sabe-se, porém, que os fungos contribuem para a produção de grãos ardidos.

\section{HOSPEDEIROS}

As duas espécies identificadas como $S$. maydis e $S$. macrospora parasitam plantas de milho (Sutton \& Waterston, 1964a,b; White, 1999). A espécie S. maydis também foi encontrada em bambú (Arundinaria sp.) (Sutton \& Waterston, 1966a; Sutton, 1980). Na literatura nacional a maior parte 
dos trabalhos não menciona os hospedeiros para essas duas espécies, assumindo que o milho é considerado o único hospedeiro (Costa Neto, 1976; Pinto et al., 1997; Fernandes et al., 1997; Reis et al., 2004; Pereira et al., 2005).

\section{SINTOMATOLOGIA}

A podridão de semente, a morte de plântula e a podridão radicular ocorrem em menor freqüência. A podridão de semente normalmente ocorre devido a colonização do fungo no embrião da semente (McGee, 1988; Casa, 1997).

No caso de podridão do colmo, os sintomas secundários manifestam-se várias semanas após a polinização. Os entrenós basais das plantas infectadas apresentam lesões externas, de forma localizada, de cor parda a escura, iniciando preferencialmente nos nós (Figura 1B). Um sinal importante para a diagnose da doença é a presença de picnídios, subepidérmicos, pequenos, pardo-negros, agrupados nas lesões próximas aos tecidos dos nós, principalmente quando o tecido encontra-se senescido. As folhas das plantas infectadas murcham, tornando-se verde-acinzentada e secas, semelhante ao dano causado por geada. $\mathrm{O}$ quadro sintomatológico inclui alteração da cor externa do colmo, parte interna dos nós e desintegração da medula, deixando apenas os feixes vasculares intactos. As plantas severamente atacadas podem ser prematuramente mortas.

$\mathrm{Na}$ espiga, os sintomas iniciam, principalmente, na base da espiga (Figura 1C) logo após a fecundação. As brácteas da espiga tornam-se despigmentadas e de coloração parda. Quando a infecção ocorre duas semanas após a polinização, toda a espiga pode tornar-se podre, apresentando coloração pardocinzenta a esbranquiçada (Figura 1D), enrugada e leve, com as palhas internas fortemente aderidas umas as outras ou aos grãos, devido ao crescimento do micélio do fungo. Os picnídios negros podem formar-se sobre a palha, brácteas florais, sabugo e grãos. Os grãos infectados apresentam cor cinza fosco a marrom. As espigas infectadas ao final do ciclo da cultura não mostram sintomas externos e, quando são despalhadas e os grãos assintomáticos removidos, o micélio branco pode ser visto crescendo entre os grãos remanescentes nas espigas. Alguns isolados de S. maydis induzem a viviparidade, ou seja, a germinação prematura dos grãos. Também foi verificado que as plantas com podridão do colmo normalmente apresentam as espigas com a ponta voltada para baixo. Tanto no colmo como na espiga não é possível determinar se a infecção foi causada por S. maydis ou S. macrospora apenas com base nos sintomas. A diagnose correta é feita com base nas características dos esporos das duas espécies.

Os sintomas de mancha foliar são característicos da espécie S. macrospora (Ram et al., 1973; Marasas \& Van Der Westhuizen, 1979; Latterell \& Rossi, 1983). As lesões iniciais em alguns híbridos apresentam-se na forma de tecido clorótico seguido de necrose. As lesões têm formato irregular, medem normalmente de 1 a $3 \mathrm{~cm}$ de comprimento, apresentam cor parda e podem apresentar anéis concêntricos mais escuros a partir do ponto inicial de infecção (Figura 1E). As primeiras lesões também podem ser visualizadas na forma de pequenas estrias avermelhadas ou pardas que, mais tarde, aumentam de tamanho estendendo-se no sentido longitudinal da folha, podendo dilacerar o tecido vegetal infectado (Figura 1F). Sobre o tecido necrosado são observados os picnídios do fungo na forma de pequenos pontos negros, subepidérmicos, isolados ou agrupados. Sob clima úmido, com o auxílio de lupa de mão, podem ser observados os cirros longos extrudando dos picnídios. Os esporos produzidos sobre as lesões podem ser transportados pela água até a bainha foliar onde, posteriormente, germinam e iniciam a infecção do colmo ou da base da espiga.

\section{CICLO BIOLÓGICO DE Stenocarpella macrospora e de $S$. maydis}

\section{Fontes de inóculo}

Os fungos $S$. macrospora e $S$. maydis são fungos necrotróficos, apresentando fase parasitária na planta viva e fase saprofitica em restos culturais. Dessa maneira, os patógenos são encontrados sobrevivendo fora do período de cultivo como micélio no interior das sementes (McGee, 1988; Casa et al., 1998a, Rheeder et al., 1990) e formando picnídios nos restos culturais sobre a superficie do solo (Smith \& White, 1988; Shurtleff, 1992; Reis \& Casa, 1996).

As sementes infectadas constituem-se em fonte de inóculo primário para podridão de semente, morte de plântulas e podridão de raízes. Tanto S. maydis (McNew, 1937; McGee, 1988) como $S$. macrospora (Casa et al., 1998b) podem ser transmitidos à plântula. No entanto, a taxa de transmissão desses fungos ainda não foi quantificada. A transmissão é fundamental em lavouras onde o milho nunca foi semeado ou em áreas de rotação de culturas, pois indica o potencial de inóculo da semente no desenvolvimento inicial de epidemias. O processo de transmissão de S. macrospora e $S$. maydis ocorre com o micélio do fungo colonizando o sistema radicular e a base do colmo. A passagem do fungo da semente, via mesocótilo, alcançando a coroa, raízes e finalmente a base do colmo, é um processo lento que quase coincide com o ciclo da cultura (Casa et al., 1998b). A associação dos patógenos a sementes garante acesso direto do parasita à fonte nutricional por ocasião da germinação das sementes e emergência das plântulas.

Os restos culturais de milho infectados por S. maydis e $S$. macrospora, que permanecem na superficie do solo de uma estação de cultivo para a outra, são considerados a principal fonte de inóculo primário para as podridões do colmo e da espiga e para mancha foliar. Na palha, os fungos sobrevivem formando picnídios, produzindo e liberando cirros de conídios (Figura $1 \mathrm{G})$, que constituem o inóculo primário para as plantas do novo cultivo. Durante os anos de 1962 e 1963, em Indiana, Estados Unidos, verificou-se a ocorrência de duas epifitias da podridão branca da espiga do milho causada por $S$. maydis, limitadas em extensão com uma redução na intensidade da doença a partir da fonte de inóculo, constituída de palha infectada dos anos anteriores (Ullstrup, 1964). Na África do Sul, uma relação linear positiva entre a incidência da podridão branca da espiga e a quantidade de resíduo na superfície do solo foi relatada por Flett et al. (1998).

As maiores intensidades da podridão do colmo e da 
espiga ocorrem nas situações onde as plantas se encontram próximas da fonte de inóculo (Ullstrup, 1964; Flett et al., 1992. Incidência de 49 a $61 \%$ de podridão da espiga, causada por $S$. maydis, foi detectada em lavoura localizada ao lado da fonte de inóculo, sendo que a incidência baixou para menos de $1 \%$ em lavouras localizadas a $16 \mathrm{~m}$ da fonte de inóculo. Del Rio \& Melara (1991) relataram redução de $80 \%$ na incidência de podridão da espiga causada por $S$. maydis em plantas distantes $20 \mathrm{~m}$ da fonte de inóculo constituída por palha infectada. Mário et al. (1998) demonstraram que o inóculo de S. maydis e $S$. macrospora, produzido nos restos culturais sobre o solo e dispersado pelo vento, relaciona-se com a incidência dos fungos na semente colhida.

Uma possível fonte de inóculo alternativa seria os hospedeiros secundários. Entretanto, segundo a literatura consultada, somente as plantas de bambú seriam parasitadas por $S$. maydis. Como a população dessa planta é muito restrita limitandose a pequenos bosques em determinadas regiões, provavelmente essas têm pouca importância como fonte de inóculo.

Nemec (1992) e Scott (1993) consideram S. maydis e $S$. macrospora como fungos de solo, tendo como critério a sobrevivência saprofitica nos restos culturais. Esses autores não consideram a necessidade de estruturas especiais de descanso ou a probabilidade de sobreviverem como conídios livres como critério para incluir as duas espécies como fungo de solo.

\section{Disseminação}

A semente infectada é um dos principais veículos de disseminação de $S$. maydis e $S$. macrospora sendo responsável pela introdução dos fungos em novas áreas de cultivo, mesmo distantes de seu local de produção, como detectado pelo serviço de quarentena do Japão em sementes importadas dos Estados Unidos (Dai et al., 1987). MacDonald \& Chapman (1997), em testes de sanidade de sementes de diferentes países, detectaram com freqüência a presença dos fungos $S$. maydis e S. macrospora.

A dispersão vertical e horizontal dos conídios de S. maydis e $S$. macrospora, a partir dos restos culturais naturalmente infectados foi recentemente relatada por Casa et al. (2004). Em relação a dispersão vertical, os dados da coleta de esporos foram obtidos diariamente às $8: 00 \mathrm{~h} \mathrm{e}$ 20:00 h, durante 62 dias consecutivos. O número acumulado de conídios de $S$. maydis com lâmina removida às $20: 00 \mathrm{~h}$ foi inversamente proporcional a distância da fonte de inóculo, sendo o melhor ajuste do gradiente de inóculo obtido pelo modelo proposto por Gregory ( $\left.\mathrm{y}=79.011 \mathrm{x}^{-0,9973}, \mathrm{R}^{2}=0,88\right)$. Durante a noite não foi observada essa tendência. Para $S$. macrospora, o número de conídios coletados diminuiu à medida que aumentou a altura dos coletores, tanto de dia $\left(\mathrm{y}=4.108,4 \mathrm{x}^{-0,4701}, \mathrm{R}^{2}=0,96\right)$ como de noite $\left(\mathrm{y}=2.333,5 \mathrm{x}^{-}\right.$ ${ }_{0,9182}, \mathrm{R}^{2}=0,88$ ), sendo que o modelo de Gregory se ajustou muito bem para explicar a análise de dispersão do inóculo. Os dados demonstraram que mais de $60 \%$ dos conídios de $S$. maydis e $S$. macrospora foram coletados até uma altura de $25 \mathrm{~cm}$. Esses valores ajudam a compreender porque as podridões causadas por Stenocarpella em milho apresentam sintomas freqüentes e típicos na base do colmo, normalmente no primeiro e segundo entrenó. Cabe salientar que esses sintomas também podem ser evidentes no final do ciclo da cultura caso ocorra a transmissão dos fungos da semente para a planta. Com altura superior a $50 \mathrm{~cm}$ verificou-se uma coleta de 20 a $30 \%$ dos conídios de ambos os fungos, indicando uma redução de mais de $50 \%$ quando comparado com a altura de até $25 \mathrm{~cm}$. Possivelmente, o tamanho e o peso dos conídios e/ou do cirro inteiro liberado do picnídio, e/ou a altura do respingo do impacto da gotícula d'água sobre o corpo frutífero contendo o inóculo não permitam que sejam dispersados abundantemente a alturas superiores a $25 \mathrm{~cm}$ da fonte de inóculo. Os conídios de Stenocarpella capturados acima de $50 \mathrm{~cm}$ de altura possivelmente são responsáveis por uma das vias de inoculação dos fungos nas espigas. Nessa situação, na lavoura, os conídios dispersos pelo vento são depositados pela força gravitacional na bainha foliar. Mário et al. (1998) determinaram que os esporos produzidos nos restos culturais foram responsáveis pela infecção de grãos de milho no campo. Os conídios de S. macrospora coletados $50 \mathrm{~cm}$ acima da fonte de inóculo provavelmente são responsáveis pela infecção das folhas do milho, causando sintoma de mancha foliar. Na dispersão horizontal os esporos dos fungos foram capturados nas armadilhas até uma distância de $120 \mathrm{~m}$ da fonte de inóculo (Casa et al. 2004). O modelo de dispersão de inóculo proposto por Kiyosawa \& Shiyomi foi o que melhor se ajustou tanto para $S$. maydis $\left(\mathrm{y}=30,757 \mathrm{e}^{-0,025 \mathrm{x}}, \mathrm{R}^{2}=0,70\right)$ como para S. macrospora $\left(\mathrm{y}=8,6301 \mathrm{e}^{-0,0244 \mathrm{x}}, \mathrm{R}^{2}=0,88\right)$, assumindo uma diminuição exponencial da captura de conídios a partir da fonte de inóculo. Apesar de ter-se capturado esporos distantes $120 \mathrm{~m}$ da palha infectada, dificilmente esse inóculo seria suficiente para causar epidemia, pois a freqüência e a quantidade de esporos capturados pode ser considerada baixa.

\section{Inoculação e colonização}

Considera-se que a podridão de semente e a morte de plântulas causada por Stenocarpella spp. tenham as sementes como a sua principal fonte de inóculo. Quando a semente é hidratada, ao entrar em contato com a água do solo, o micélio do fungo, que se encontra no endosperma ou no embrião, reassume sua atividade vital e passa a crescer do interior à superficie da semente. Ao crescer sobre a semente, o fungo acaba alcançando as raízes e o coleóptilo das plantas, pela colonização do coleóptilo atinge a superfície do solo.

A podridão da base do colmo pode ter origem com a infecção nos órgãos abaixo do nível do solo, a partir do inóculo presente nas sementes infectadas (McNew, 1937) ou nas raízes infectadas (Craig \& Hooker, 1961). De modo geral, o processo mais freqüente de infecção dos colmos, ocorre com inóculo proveniente dos resíduos culturais. A velocidade de colonização de $S$. maydis em colmos inoculados é maior uma a três semanas após a antese (Hooker, 1957), sendo inibida em tecidos com células vivas (Pappelis \& Smith, 1963), predominantes nos entrenós dos colmos antes da floração. Chambers (1988) 
demonstrou não haver diferença significativa entre a podridão medular do colmo com inoculações na metade do período de polinização e 18 dias após. Segundo Latterell \& Rossi (1983), $S$. macrospora coloniza mais facilmente colmos e espigas jovens, no entanto, para $S$. maydis a infecção é maior algumas semanas após a polinização.

Normalmente a infecção da espiga ocorre a partir de esporos disseminados pelo vento, que ao germinarem na presença de água sobre o tecido do hospedeiro, emitem o tubo germinativo, penetrando diretamente a palha da espiga (Shurtleff et al., 1976; Bensch, 1995). Bensch et al. (1992) determinaram que suspensão de conídios de $S$. maydis inoculada no colmo atrás da espiga no período de polinização, resulta na maior incidência da podridão da espiga. Por outro lado, Klapproth \& Hawk (1991) obtiveram maior nível de infecção com injeção da suspensão de esporos de $S$. maydis dentro da espiga. Posteriormente, Bensch (1995) determinou que a colonização do fungo na base da espiga com posterior ramificação do micélio para a ponta da mesma, ocorreu pela inoculação dos conídios de S. maydis entre a bainha foliar e o colmo. A infecção natural ocorre principalmente no período de duas a três semanas após a polinização, com clima úmido e temperatura de $28-30{ }^{\circ} \mathrm{C}$ (Shurtleff, 1992). No caso de S. macrospora, a infecção da base das espigas pode ter origem com inóculo produzido sobre as lesões foliares e transportado pela água até a bainha foliar.

A germinação dos conídios de S. maydis sobre os tecidos do colmo e da bainha foliar ocorreu após $5 \mathrm{~h}$ de incubação a $30^{\circ} \mathrm{C}$ (Bensch et al., 1992), com penetração e colonização da hifa do fungo inter e intracelular. A colonização foi acompanhada pela degeneração das paredes da célula, demonstrando haver atividade de enzimas.

$\mathrm{O}$ alto nível de $\mathrm{N}$ e baixo de $\mathrm{K}$, a alta densidade de plantas e a redução da área foliar devido a outras doenças, o granizo ou danos por insetos, podem também predispor as plantas à infecção de Stenocarpella (Dodd, 1980; Smith \& White, 1988).

$\mathrm{O}$ efeito da temperatura e do período luminoso no crescimento do micélio, na germinação de esporos e na liberação do cirro de conídios de S. macrospora e S. maydis, em condições controladas, foi recentemente determinada por Casa et al. (submetido). A faixa de temperatura entre 23 e $28{ }^{\circ} \mathrm{C}$ proporcionou maior crescimento do micélio das duas espécies, tanto sob luz contínua como sob fotoperíodo de $12 \mathrm{~h}$. Não se observou crescimento do micélio em temperatura inferior a $10{ }^{\circ} \mathrm{C}$ e superior a $40{ }^{\circ} \mathrm{C}$. Considerando o regime luminoso, constatouse que o micélio dos fungos cresceu mais rapidamente sob fotoperíodo de $12 \mathrm{~h}$. Os conídios de S. macrospora e $S$. maydis não germinaram após $24 \mathrm{~h}$ de incubação nas temperaturas de 5 e $45{ }^{\circ} \mathrm{C}$, independentemente do fotoperíodo. As temperaturas entre 28 e $33^{\circ} \mathrm{C}$ propiciaram a maior porcentagem de germinação dos conídios de $S$. maydis, enquanto que para $S$. macrospora a germinação ocorreu com temperatura mais baixa, numa faixa de 26 a $29{ }^{\circ} \mathrm{C}$. Os esporos de ambas as espécies germinaram mais rapidamente na presença da luz. A liberação do cirro através do ostíolo do picnídio, em pedaços de colmos de milho, foi maior na faixa térmica de 30 a $35{ }^{\circ} \mathrm{C}$ sob luz contínua, para as duas espécies.

\section{Sobrevivência}

$\mathrm{O}$ armazenamento da semente infectada garante a sobrevivência do patógeno até o momento da semeadura, quando recebe os estímulos do ambiente para iniciar o processo de germinação. Os fungos $S$. maydis e $S$. macrospora sobrevivem principalmente na forma de micélio no endosperma e no embrião das sementes de milho. Casa et al. (1998a) relataram uma freqüência média de 18,5 e 21,4\% de Stenocarpella spp. em sementes de milho produzidas em lavouras do sul e do sudeste do Brasil, safra 94/95 e 95/96, respectivamente, tratadas comercialmente com fungicidas.

Os fungos $S$. maydis e $S$. macrospora também sobrevivem saprofiticamente na resteva de milho, colonizando os tecidos celulares e formando picnídios subepidérmicos. No sistema plantio direto os restos culturais do milho são deixados na sua totalidade sobre a superfície do solo. O posicionamento da palha sobre o solo torna sua decomposição mais lenta, o que aumenta o período de sobrevivência dos patógenos necrotróficos durante a fase saprofítica (Casa, 2000; Casa et al., 2003). Dessa maneira, o inóculo encontra-se num posicionamento ideal para esporulação, liberação e dispersão. Por isso, a intensidade de diplodia no sistema plantio direto é maior sob monocultura (Mora \& Moreno, 1984; Flett \& Wehner, 1991). O desenvolvimento e o período de sobrevivência de picnídios de $S$. maydis são maiores nos restos culturais na superfície do solo (Flett et al., 1992). Esses autores verificaram 11 meses após a colheita a produção de 90,6 e 37,9 picnídios $/ \mathrm{cm}^{2}$ de palha e 39,5 e $24,3 \%$ de esporos germinados, respectivamente, para os restos culturais remanescentes na superfície do solo e enterrados. Casa et al. (2003) detectaram uma viabilidade de $S$. macrospora e $S$. maydis superior a $90 \%$ em colmos de milho mantidos na superfície do solo até 320 dias de exposição no campo.

Pouco se conhece a respeito da possibilidade de S. maydis e $S$. macrospora sobreviverem como conídios ou clamidosporos livres no solo. Craig \& Hooker (1961) infestaram o solo com S. maydis, em casa-de-vegetação, e observaram em estudo histológico que a infecção do colmo pode se processar a partir de raízes infectadas, pelo inóculo presente no solo. Casa (1997) observou a morte de plantas e sintomas de podridão radicular 21 dias após a infestação do solo com conídios de $S$. maydis e S. macrospora. Nesse caso, utilizou-se solo autoclavado, com semeadura do milho logo após a adição do inóculo no solo, demonstrando a capacidade dos conídios presentes livres no solo em parasitar às plântulas. No entanto, não se conseguiu posteriormente determinar a densidade de inóculo no solo e a viabilidade dos conídios após a retirada das plantas, demonstrando a necessidade de mais estudos para esclarecer a possibilidade dos conídios livres no solo constituíremse em fonte de inóculo. 


\section{CONTROLE}

O fato de que S. macrospora e S. maydis infectam exclusivamente plantas de milho, não formam estrutura de repouso e apresentam conídios dispersados a curtas distâncias, constituem-se em características biológicas dos patógenos que propiciam manejar a doença reduzindo ou eliminando o inóculo na sua fonte, como por exemplo, o uso de sementes sadias ou tratadas com fungicidas em dose eficiente e a rotação de culturas.

\section{Cultivar resistente}

A resistência genética de plantas de milho a Stenocarpella vem sendo investigada há décadas em diversas partes do mundo (Koehler, 1951; Pappelis et al., 1973; Anderson \& White, 1994), principalmente por técnicas de inoculação em diferentes sítios de infecção e em diferentes estádios de desenvolvimento da planta (Foley, 1960; Ullstrup, 1970; Pereira \& Pereira, 1976; Chambers, 1988; Klapproth \& Hawk, 1991; Bizzetto et al., 2000), o que esclareceram em parte os processos de infecção, colonização e expressão dos sintomas em diversos cultivares testados, apesar da dificuldade de repetibilidade do grau de resistência (Flett \& McLaren, 1994; Van Rensburg \& Ferreira, 1997).

Aredução do nível de açúcar no colmo das plantas de milho determina a senescência destes, que é indicada pela diminuição da densidade da medula. As plantas com tecido senescido estão mais predispostas aos agentes causais das podridões do colmo (Craig \& Hooker, 1961), sendo que, aparentemente, a síntese celular de substâncias de resistência diminui (Be Miller \& Pappelis, 1965). Dodd (1980) também relata que a senescência ou a morte celular dos tecidos precede à podridão do colmo. No caso de espigas, Koehler (1951) relacionou a resistência à podridão com o bom empalhamento da espiga.

No Brasil, os híbridos comerciais de milho foram classificados quanto à sua resistência às podridões do colmo (Denti et al., 2002) e da espiga, e em algumas situações em relação à incidência de grãos ardidos. Entretanto, não existe uma descrição clara da reação dos materiais genéticos especificamente para cada patógeno. Mário et al. (1998), avaliando a reação de resistência a S. macrospora em 196 genótipos de milho, determinaram que $37 \%$ foram resistentes e 63\% apresentaram reação intermediária a suscetível à mancha de macrospora. No caso de podridão da espiga, o híbrido X 9403 apresentou menor incidência de $S$. maydis quando comparado com os híbridos P3041, C808, C901, XL212 e Ag9012 (Mário \& Reis, 2003).

\section{Rotação de culturas}

A prática da rotação de culturas é menos agressiva ao ambiente, contribuindo para a sustentabilidade ecológica da agricultura e viabilizando o sistema plantio direto. Sob o ponto de vista fitotécnico, a rotação de culturas se constitui na alternância regular de diferentes culturas em uma mesma área (Santos \& Reis, 2001). A rotação de culturas pode ser definida como a alternância ordenada de diferentes espécies de plantas, num espaço de tempo, na mesma área, obedecendo, finalidades definidas, sendo que uma espécie vegetal não é repetida, no mesmo lugar, com intervalo menor que dois e, se possível, três ou mais anos (Derpsch, 1985). Por outro lado, sob o ponto de vista fitopatológico, rotação de culturas consiste na semeadura de uma espécie vegetal, num mesmo local da lavoura, na mesma estação de cultivo, onde os restos culturais do cultivo anterior foram eliminados biologicamente (Reis \& Casa, 1996; Zambolim et al., 2000). Nesta situação, a palha foi eliminada pela ação decompositora de microrganismos do solo; foi biologicamente degradada de tal maneira que o inóculo dos agentes necrotróficos presentes na resteva e que não formem estrutura de repouso, tenha sido eliminado ou mantido abaixo do limiar numérico de infecção. Contrariamente, monocultura consiste no cultivo da mesma espécie vegetal, no mesmo local da lavoura, onde estão presentes seus próprios restos culturais (Reis \& Casa, 1996). O cultivo do milho safrinha, no Brasil, é um sistema onde a mesma espécie vegetal cultivada em sucessão no mesmo ano agrícola. Neste caso, o cultivo do milho safrinha pode determinar a severidade máxima de uma doença.

A incidência e a severidade da mancha de macrospora, podridão do colmo de diplodia e podridão branca da espiga está relacionada com quantidade de resíduos culturais presentes na superfície do solo. Dessa maneira, o milho somente deverá voltar a ser cultivado na mesma lavoura quando a densidade de inóculo estiver abaixo do limiar numérico de infecção, ainda não determinado, ou após a eliminação completa dos restos culturais. Casa et al. (2003) observaram a viabilidade de $S$. macrospora e $S$. maydis em colmos de milho mantidos na superfície do solo até 320 dias de exposição no campo. Portanto, a rotação de culturas com espécies vegetais não suscetíveis por período aproximado de duas safras constitui-se numa estratégia eficiente para o controle de diplodia. Como outros patógenos podem infectar o milho, torna-se importante a escolha de espécies vegetais alternativas que possam integrar o sistema de rotação de culturas. Geralmente, as espécies de plantas de folhas largas, como por exemplo a soja e o feijão, são as culturas que integram o sistema de rotação visando à exploração econômica da atividade agrícola.

\section{Controle do patógeno associado a semente}

Em lavoura de plantio direto, conduzida sob rotação de culturas, o controle de diplodia obrigatoriamente deve ser feito pelo uso de semente sadia e/ou pelo tratamento de semente com fungicida que leve a erradicação dos fungos. $\mathrm{O}$ tratamento de sementes de milho com fungicidas têm como objetivo controlar fungos associados a semente e protegê-las contra aqueles do solo (Casa et al., 1995; Reis et al., 1995; Pinto, 1996). A finalidade do controle é prevenir a deterioração da semente e evitar a transmissão do patógeno das sementes infectadas para as plântulas, evitando ou reduzindo a intensidade de podridões de raízes e da base do colmo. A erradicação de $S$. maydis e $S$. macrospora pelo tratamento de sementes de milho pode ser obtida com o uso de fungicidas do grupo dos benzimidazóis, utilizando-se a dose de 40 a 50 gramas de ingrediente ativo para $100 \mathrm{~kg}$ de sementes (Casa et al., 1998b). 


\section{Balanço adequado da fertilidade do solo}

Após a floração do milho o fluxo de carbohidratos dentro da planta é direcionado prioritariamente ao enchimento de grãos. Quando, em algumas situações, a planta não produz carbohidratos em quantidade suficiente, a competição leva os tecidos da raíz e da base do colmo a senescerem precocemente. Na medida que as células iniciam o processo de senescência, seus tecidos tornam-se mais predispostos à colonização pelos fungos. A disponibilidade de nitrogênio $(\mathrm{N})$ e de potássio (K) em quantidade suficiente para satisfazer a demanda gerada pelo metabolismo da planta durante todo o período de crescimento é um aspecto chave para o manejo das podridões do colmo, na medida que o balanço e o fornecimento contínuo de $\mathrm{N}$ mantém as células da medula ativa por um período mais longo de tempo. O potássio dos estómatos está envolvido com as funções bem como as vias metabólicas. Quando a planta encontra-se deficiente de $\mathrm{K}$, a taxa de fotossíntese é reduzida, o que pode resultar na senescência mais rápida da medula (Smith \& White, 1988; White, 1999). Foley \& Wernham (1954) determinaram que uma alta relação de N:K (200:0) aumentou a severidade da podridão do colmo, a porcentagem de quebra destes e a morte prematura das plantas. No caso somente de N, White et al. (1978) mostraram que a podridão do colmo diminuiu com o aumento crescente das doses de N. Especificamente para diplodia estudos são necessários para determinar a relação entre a incidência e a severidade de doença e o estado nutricional das plantas de milho.

\section{População de plantas}

Em geral, o incremento na população de plantas tem aumentado a intensidade das podridões do colmo e da espiga. À medida que a população de plantas aumenta, a demanda por nutrientes e água também é incrementada, e quando não for devidamente suprida qualitativa e quantitativamente pode predispor as plantas à infecção. Denti $\&$ Reis (2001) relataram que, independentemente da rotação ou da monocultura, o aumento populacional determinou uma maior incidência das podridões do colmo. Trento et al. (2002) verificaram uma relação linear entre a população de plantas e a incidência de grãos ardidos. Nestes trabalhos, os autores estudaram populações de 30, 40, 50, 60 e 70 mil plantas ha ${ }^{-1}$ em sistema plantio direto em monocultura e em rotação de culturas com soja e verificaram uma maior incidência de podridões do colmo e de grãos ardidos em monocultura, comparado à rotação de culturas. Blum et al. (1998) também relataram um aumento de aproximadamente 5\% na incidência de grãos ardidos quando a população de

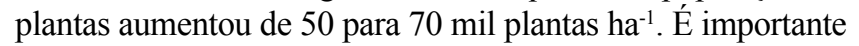
ressaltar que a população final de plantas interfere diretamente na produção da cultura do milho. Dessa maneira, antes de se reduzir a população de plantas como uma alternativa para o manejo das doenças causadas por estes agentes patogênicos, deve-se levar em consideração o potencial de produtividade do híbrido, analisando-se a relação entre custo-benefício entre a porcentagem de redução na produtividade e os ganhos resultantes da redução na incidência de grãos ardidos.

\section{REFERÊNCIAS BIBLIOGRÁFICAS}

ANDERSON, B. \& WHITE, D.G. Fungi associated with cornstalks in Illinois in 1982 and 1983. Plant Disease 71:135-137. 1987.

ANDERSON, B. \& WHITE, D.G. Evaluation of methods for identification of corn genotypes with stalk rot and lodging resistance. Plant Disease 78:590-593. 1994.

BALMER, E. \& PEREIRA, O.A.P. Doenças do milho. In: Paterniani, E. \& Viegas, G.P. (Eds.) Melhoramento e produção do milho. 2.ed. Campinas, SP. Fundação Cargill, 1987. v.2. pp. 595-634.

BE MILLER, J.N. \& PAPPELIS, A.J. 2,4-Dihydroxy-7methoxy-1,4benzoxazin-3-one glicoside in corn. I. Relation of water-soluble, 1butanol-soluble glycoside fraction content of pith cores and stalk rot resistance. Phytopathology 55:1237-1240. 1965.

BENSCH, M.J. Stenocarphella maydis (Berk.) Sutton colonization of maize ears. Journal of Phytopathology 143:597-599. 1995.

BENSCH, M.J., VAN STADEN, J. \& RIJKENBERG, F.H.J. Time and site inoculation of maize for optimum infection of ears by Stenocarpella maydis. Journal of Phytopathology 136:265-269. 1992.

BIZZETTO, A., HOMECHIN, M. \& SILVA, H.P. Técnicas de inoculação de Diplodia maydis em milho. Fitopatologia Brasileira 25:21-29. 2000.

BLUM, M.M.C., FONTOURA, S.M.V., NOVATIZKI, M.R. \& CLAZER, E.R. Efeito de doses de nitrogênio e população de plantas sobre a incidência de fungos na semente de milho colhida. In: Simpósio Brasileiro de Patologia de Sementes, 5, Ponta Grossa, PR, 1998. Sanidade de Sementes no Século XXI. Programa \& Resumos. Ponta Grossa, PR. pp. 27.

CASA, R.T. Diplodia maydis e Diplodia macrospora associados a semente de milho. Dissertação de Mestrado. Viçosa, MG. Universidade Federal de Viçosa. 1997.

CASA, R.T. Sobrevivência de Stenocarpella maydis e Stenocarpella macrospora em restos culturais de milho. Tese de Doutorado. Viçosa, MG. Universidade Federal de Viçosa. 2000.

CASA, R.T., REIS, E.M., MEDEIROS, C.A. \& MOURA, F.B. Efeito do tratamento de sementes de milho com fungicidas na proteção de fungos do solo no Rio Grande do Sul. Fitopatologia Brasileira 20:633-638. 1995.

CASA, R.T., REIS, E.M. \& ZAMBOLIM, L. Fungos associados a semente de milho produzida nas Regiões Sul e sudeste do Brasil. Fitopatologia Brasileira 23:370-373. 1998a.

CASA, R.T., ZAMBOLIM, L. \& REIS, E.M. Transmissão e controle de diplodia em sementes de milho. Fitopatologia Brasileira 23:436-441. 1998b.

CASA, R.T., REIS, E.M., SEVERO, R., DENTI, E., TRENTO, S. \& BLUM, M.M.C. Prevenção e controle de doenças na cultura do milho. In: Sandini, I.A. \& Fancelli, A.L. (Eds.) Milho: estratégias de manejo para a região sul. Guarapuava. Fundação Agrária de Pesquisa Agropecuária. 2000.

CASA, R.T., REIS, E.M. \& ZAMBOLIM, L. Decomposição dos restos culturais do milho e sobrevivência saprofítica de Stenocarpella macrospora e Stenocarpella maydis. Fitopatologia Brasileira 28:355-361. 2003.

CASA, R.T., REIS, E.M. \& ZAMBOLIM, L. Dispersão vertical e horizontal de conídios de Stenocarpella macrospora e Stenocarpella 
maydis. Fitopatologia Brasileira 29:141-147. 2004.

CASA, R.T., REIS, E.M. \& ZAMBOLIM, L. Efeito da temperatura e de regimes de luz no crescimento do micélio, germinação de conídios e esporulação de Stenocarpella macrospora e Stenocarpella maydis. Fitopatologia Brasileira (submetido).

CHAMBERS, K.R. Effect of time of inoculation on Diplodia stalk and ear rot of maize in South Africa. Plant Disease 72:529-531. 1988.

CLAYTON, E.E. Diplodia ear rot disease of corn. Journal Agricultural Research 34:357-371. 1927.

CONAB. Indicadores da Agropecuária. Extraído de www.conab. com.br em 10/07/06.

COMMITTEE ON STANDARDIZATION OF COMMON NAMES FOR PLANT DISEASES. Common names for plant diseases. Plant Disease 69:649-676. 1985.

COSTA NETO, J.P. Lista de fungos sobre gramineae (capins e cereais) no Rio Grande do Sul. Revista da Faculdade de Agronomia (UFRGS) 1:43-78. 1976.

CRAIG, J. \& HOOKER, A.L. Diplodia root and stalk rot of dent corn. Phytopathology 51:382-385. 1961.

CUTler, H.G., CRUMley, F.G., COX, R.H., COLE, R.J., DORNER, J.W., LATTERELL. F.M. \& ROSSI, A.E. Diplodiol: a new toxin from Diplodia macrospora. Journal Agricultural Food and Chemistry 28:135-138. 1980.

DAI, K., NAGAI, M., SASAKI, H., NAKAMURA, H., TACHECHI, K. \& WARABI, M. Detection of Diplodia maydis (Berkeley) Saccardo from imported corn seed. Research Bulletin of the Plant Protection Service 23:1-6. 1987.

DEL RÍO, L. \& MELARA, W. Dispersion de Stenocarpella maydis (Berk.) Sutton en un cultivo de maíz. Ceiba 32:133-140. 1991.

DENTI, E. \& REIS, R.T. Efeito da rotação de culturas, da monocultura e da densidade de semeadura de plantas na incidência das podridões da base do colmo e no rendimento de grãos de milho. Fitopatologia Brasileira 26:635-639. 2001.

DENTI, E. \& REIS, E.M. Levantamento de fungos associados às podridões do colmo e quantificação de danos em lavouras de milho do planalto médio gaúcho e dos campos gerais do Paraná. Fitopatologia Brasileira 28:585-590. 2003.

DENTI, E., REIS, E.M. \& FORCELINI, C.A. Reação de genótipos de milho às podridões da base do colmo. Summa Phytopathologica 28:286-288. 2002.

DERPSCH, R. Adubação verde e rotação de culturas. In: Encontro Nacional de Plantio Direto, 3, 1985, Ponta Gossa, Anais... Ponta Grossa: Fundação ABC, 1985. pp. 85-104.

DODD, J.L The role of plant stresses in development of corn stalk rots. Plant Disease 64:533-537. 1980.

DORRANCE, A.E., MILLER, O.K. \& WARREN, H.L. Comparison of Stenocarpella maydis isolates for isozyme and cultural characteristicis. Plant Disease 83:675-680. 1999.

EARLE, F.S. New species of fungi imperfect from Alabama. Bulletin Torrey Botanical Club 24:28-32. 1897.

EDDINS, A.H. Dry rot of corn caused by Diplodia macrospora Earle. Phytophatology 20:439-448. 1930.

FERNANDES, F.T. \& OLIVEIRA, E. de. Principais doenças na cultura do milho. Sete Lagoas MG. Embrapa-CNPMS. Circular Técnica, 26. 1997.

FLETT, B.C. \& WEHNER, F.C. Incidence of Stenocarpella and Fusarium cob rots in monoculture maize under different tillage systems. Journal of Phytopathology 133:327-333. 1991.

FLETT, B.C., WEHNER, F.C. \& SMITH, M.F. Relationship between maize stubble placement in soil and survival of Stenocarpella maydis (Diplodia maydis). Journal of Phytopathology 134:33-38. 1992.

FLETT, B.C. \& McLAREN, N.W. Optimum disease potencial for evaluating resistance to Stenocarpella maydis ear rot in corn hybrids. Plant Disease 78:587-589. 1994.

FLETT, B.C., McLAREN, N.W. \& WEHNER, F.C. Incidence of ear rot pathogens under alternating corn tillage practices. Plant Disease 82:781-784. 1998.

FOLEY, D.C. The response of corn to inoculation with Diplodia zeae and Giberella zeae. Phytopathology 50:146-150. 1960

FOLEY, D.C. \& WERNHAM, C.C. The effect of fertilizers on stalk rot of corn in Pennsylvania. Phytopathology 47:11-12. 1957.

HOOKER, A.L. Factors affecting the spread of Diplodia zeae in inoculated corn stalks. Phytopathology 47:196-199. 1957.

HOOKER, A.L. \& WHITE, D.G. Prevalence of corn stalk rot in Illinois. Plant Disease Reporter 60:364-365. 1976.

HOPPE, P.E. Intraspecific and interspecific aversion in Diplodia. Journal Agricultural Research 53:671-680. 1936.

ITO, M.F., PARADELLA FILHO, O., SUGIMORI, M.H. \& SOAVE, J. Podridão em espiga de milho (Zeae mays L.) causada por Diplodia frumenti Ell. \& Ev. Summa Phytopathologica 5:181-185. 1979.

JOHANN, H. Diplodia macrospora em milho no Brasil. Plant Disease Reporter 19:9-10. 1935.

KLAPPROTH, J.C. \& HAWK, J.A. Evaluation of four inoculation techniques for infecting corn ear with Stenocarphella maydis. Plant Disease 75:1057-1060. 1991.

KOEHLER, B. Husk coverage and ear declination in relation to corn ear rots. Phytopathology 41:22. 1951.

KOEHLER, B. \& BOEWE, G.H. Causes of corn stalk in Illinois. Plant Disease 41:501-504. 1957.

LATTERELL, F.M. \& ROSSI, A.E. Stenocarpella macrospora (=Diplodia macrospora) and S. maydis $(=D$. maydis $)$ compared as pathogens of corn. Plant Disease 67:725-729. 1983.

LLANO, A. \& SCHIEBER, E. Diplodia macrospora on corn in Nicaragua. Plant Disease 64:797. 1980.

MACDONALD, M.V. \& CHAPMAN, R. The incidence of Fusarium moniliforme on maize from Central America, Africa and Asia during 1992-1995. Plant Pathology 46:112-125. 1997.

MARASAS, W.F.O. \& VAN DER WESTHUIZEN, G.C.A. Diplodia macrospora: the cause of leaf blight and cob rot of maize (Zea mays) in South Africa. Phytophylactica 11:61-64. 1979.

MÁRIO, J.L., PRESTES, A.M. \& REIS, E.M. Avaliação da resistência à mancha foliar de Diplodia macrospora em genótipos de milho. Fitopatologia Brasileira 22:280. 1998.

MÁRIO, J.L. \& REIS, E.M. Método simples para diferenciar Diplodia macrospora de D. maydis em testes de patologia de sementes de milho. Fitopatologia Brasileira 26:670-672. 2001.

MÁRIO, J.L. \& REIS, E.M. Reação de híbridos de milho à podridão 
branca da espiga. Fitopatologia Brasileira 28:155-158. 2003.

McGEE, D.C. Maize diseases: A reference source for seed technologists. Saint Paul MN. American Phytopathological Society. 1988.

McNEW, G.L. Crown infection of corn by Diplodia zeae. Iowa Agric. Exp. Stn. Res. Bull., 216. 1937.

MICHAELSON, M.E. \& CHRISTENSEN, J.J. Reduction in yield of corn due to stalk rot. Phytopathology 43:479. 1953.

MOLIN, R. \& VALENTINI, M.L. Simpósio sobre micotoxinas em grãos. Fundação Cargill, Fundação ABC, 1999.

MORA, L.E. \& MORENO, R.A. Cropping pattern and soil management influence on plant diseases: I. Stenocarpella macrospora leaf spot of maize. Turrialba 34:35-40. 1984.

MORANT, M.A., WARREN, H.L. \& VON QUALEN, S.K. A synthetic medium for mass production of picnidiospores of Stenocarpella species. Plant Disease 77:424-426. 1993.

MORELlO, C.L., SANTOS, G.R., MIRANDA, G.V. \& ARAÚJO, E. Fungos associados à podridão de espiga de milho, ciclo normal, no Estado do Tocantins. Fitopatologia Brasileira 19:272. 1994.

NATTI, T.A. \& WHITE, D.G. Yield losses due to anthracnose and Diplodia stalk rot of corn. Phytopathology 71:1117. 1981.

NAZARENO, N.R.X. Avaliação de perdas por podridões do colmo em milho (Zea mays L.) no estado do Paraná. Fitopatologia Brasileira 14:82-84. 1999.

NEMEC, S. The deuteromycotina: Diplodia. In: Singleton, L.L., Mihail, J.D. \& Rush, C.M. (Eds.) Methods for research on soilborne phytopathogenic fungi. Saint Paul MN. American Phytopathological Society. 1992.

OLIVEIRA, M.Z.A. \& MELLO, S.C.M. Qualidade sanitáriade sementes de milho (Zea mays) das regiões de Irecê e do Vale do Paraguaçu, Bahia. Fitopatologia Brasileira 11:283. 1986. (Resumo)

PAPPELIS, A.J. \& SMITH, F.G. Relationship of water contend and living cells to spread of Diplodia zeae in corn stalks. Phytopathology 53:1100-1105. 1963.

PAPPELIS, A.J., MAYAMA, S., MAYAMA, M., BEMILLER, J.N., MURPHY, J.A., MUMFORD, P., PAPPELIS, G.A. \& KANG, M.S. Parenchyma cell death and Diplodia maydis susceptibility in stalks and ears of corn. Plant Disease Reporter 57:308-310. 1973.

PEREIRA, O.A.P., CARVALHO, R.V. \& CAMARGO, L.E.A. Doenças do milho (Zea mays L.). In: Kimati, H., Amorim, L., Rezende, J.A.M., Bergamin Filho, A. \& Camargo, L.E.A. (Eds.) Manual de Fitopatologia. Vol. 2. Doenças das plantas cultivadas. 4ed. São Paulo SP. Agronômica Ceres. 2005. pp. 477-488.

PEREIRA, O.A.P. \& PEREIRA. W.S.P. Estudo de Diplodia zea (Schw.) Lev. e Fusarium moniliforme Sheldon em colmo de milho. Summa Phytopathologica 2:157-165. 1976.

PINTO, N.F.J. A. Patologia de sementes de milho. Sete Lagoas: EMBRAPA-CNPMS, 1998. 44p.

PINTO, N.F.J.A., FERNANDES, F.T. \& OLIVEIRA, E. In: Vale, F.X.R. \& Zambolim, L. (Eds.) Controle de doenças de plantas: grandes culturas. Viçosa, MG. 1997. pp. 821-864.

RAM, A., RAM, C. \& ROCHA, H.M. A new disease of maize in Bahia, Brazil, with special reference to its causal organism. Turrialba 23:227-230. 1973.

REIS, A.C., REIS, E.M., CASA, R.T. \& FORCELINI, C.A.
Erradicação de fungos patogênicos associados a sementes de milho e proteção contra Pythium sp. presente no solo pelo tratamento com fungicidas. Fitopatologia Brasileira 20:585-590. 1995.

REIS, E.M. \& CASA, R.T. Manual de identificação e controle de doenças de milho. Passo Fundo RS. Aldeia Norte Editora. 1996.

REIS, E.M. \& CASA, R.T. Controle de doenças fúngicas na cultura do milho, em plantio direto, no sul do Brasil. In: Borges, G. \& Borges, L.D. (Eds.) Seminário sobre tecnologia de produção e comercialização do milho. Passo Fundo, RS. Resumo de Palestras. Editora Aldeia Norte, Passo Fundo, RS. 2000. pp. 62-71.

REIS, E.M. \& CASA, R.T. Milho: manejo integrado de doenças. In: Fancelli, A.L. \& Dourado Neto, D. (Eds.) Milho: tecnologia e produtividade. Piracicaba SP. ESALQ/LPV, 2001. pp. 223-237.

REIS, E.M., CASA, R.T. \& BRESOLIN, A.C.R. Manual de diagnose e controle de doenças do milho. 2.ed. Lages SC. Graphel. 2004.

RHEEDER, J.P., MARASAS, W.F.O., WYK, P.S.VAN., TOIT, W. DU., PRETORIUS, A.J. \& SCHALKWYK, D.J. VAN. Incidence of Fusarium and Diplodia species and other fungi in naturally infected grain of South African maize cultivars. Phytophylactica 22:97-102. 1990.

SACCARDO, P.A. Sylloge fungorum. Vol 3. Michigan. Edwards Brothers. 1944.

SANTOS, H.P. \& REIS, E.M. Rotação de culturas em plantio direto. Passo Fundo RS. Embrapa Trigo. 2001.

SCOTT, D.B. Soil-borne diseases of wheat and maize in South Africa: etiological and epidemiological aspects. Applied Plant Science 7:6064. 1993.

SHURTLEFF, M.C. Compendium of corn diseases. Saint Paul MN. American Phytopathological Society. 1992. 105p.

SHURTLEFF, M.C., WORF, G.L. \& WYSONG, D.S. Disease resistance and tolerance. In: Jugenheimer, R.W. (Ed.) Corn improvement seed production and uses. New York NY. John Wiley \& Sons. 1976. pp. 259-327.

SINGH, B.M. \& SHARMA, Y.R. Evaluation of maize germplasm to Diplodia stalk rot and assesment of yield loss. Indian Phytopathology 27:202-207. 1974.

SMITH, D.R. \& WHITE, D.G. Diseases of corn. In: Sprague, G.F. \& Dudley, J.W. (Eds.) Corn and corn improvement. American Society of Agronomy. Madison, WI. 1988. pp. 687-766.

SUTTON, B.C. The coelomycetes. Commonwealth Mycological Institute, Kew, Surrey, England. 1980.

SUTTON, B.C. \& WATERSTON, J.M. Diplodia maydis. Descriptions of pathogenic fungi and bacteria, 84. London C.M.I., 1966a.

SUTTON, B.C. \& WATERSTON, J.M. Diplodia macrospora. Descriptions of pathogenic fungi and bacteria, 83. London C.M.I., 1966b.

TRENTO, S.M., IRGANG, H.H. \& REIS, E.M. Efeito da rotação de culturas, da monocultura e da densidade de plantas na incidência de grãos ardidos em milho. Fitopatologia Brasileira 27:609-613. 2002.

ULLSTRUP, A.J. Observations on two ephiphytotics of Diplodia ear rot of corn in Indiana. Plant Disease Reporter 48:414-415. 1964. 
ULLSTRUP, A.J. Methods for inoculating corn ears with Gibberella zeae and Diplodia maydis. Plant Disease Reporter 54:658-662. 1970.

VAN RENSBURG, J.B.J. \& FERREIRA, M.J. Resistance of elite maize inbred lines to isolates of Stenocarpella maydis (Berk.) Sutton. South Africa Journal Plant Soil 14:89-92. 1997.

WILCOXSON, R.D. Stalk rot in relation to yield in corn. Phytopathology 52:416-418. 1962.

WILLIAMS, K.C., BLANEY, B.J. DODMAN, R.L. \& PALMER, C.L. Assesment for animal feed of maize kernels naturally-infected predominantly with Fusarium moniliforme and Diplodia maydis. I.
Fungal isolations and changes in chemical composition. Australian Journal of Agricultural Research 43:773-782. 1992.

WHITE, D.G. Compendium of corn diseases. 3th Edition. Saint Paul MN. American Phytopathological Society. APS Press. 1999.

WHITE, D.G., HOEFT, R.G. \& TOUCHTON, J.T. Effect of nitrogen and nitrapyrin on stalk rot, stalk diameter, and yield of corn. Phytopathology 68:811-814. 1978.

ZAMBOLIM, L., CASA, R.T. \& REIS, E.M. Sistema plantio direto e doenças em plantas. Fitopatologia Brasileira 25:585-595. 2000. 